\title{
Clinicobacterial and histopathological study of chronic dacryocystitis
}

\author{
Saxena $S^{1}$, Gupta $S^{2}$, Gupta $S^{3}$, Sharma $S^{4}$, Saxena $\mathbf{R}^{5}$ \\ ${ }^{1}$ Dr S P Saxena, Associate Professor, Department of Ophthalmology, R K D F Medical College, Bhopal, \\ ${ }^{2}$ Dr Subhash C Gupta, Assistant Professor, Department of Ophthalmology, R K D F Medical College, Bhopal, \\ MP, India, ${ }^{3}$ Dr Shreya Gupta, Sr Lecturer, Department of Oral Pathology \& Microbiology, Bhabha College of \\ Dental Science, Bhopal, ${ }^{4}$ Dr Shrikant Sharma, Associate Professor, Department of Surgery, L N Medical \\ College, Bhopal, MP, India, ${ }^{5}$ Dr Rohan Saxena, Consultant Periodontist, Bhopal, MP, India.
}

Address for Correspondence: Dr Subhash Gupta, Email: drsubhashgupta@rediffmail.com

\begin{abstract}
Introduction: Diseases of lacrimal drainage system account for nearly $3 \%$ of visits to eye clinic. Chronic dacryocystitis is a frequently encountered disorder among these patients. The aim of this study was to identify the organisms responsible and to determine the antibiotic susceptibility pattern of the bacterial isolates from conjunctiva and nasal mucosa in cases of chronic dacryocystitis and comparing with lacrimal sac specimen. Material and Methods: Prospective longitudinal study carried out in 40 cases suffering from chronic dacryocystitis. After complete history and local examination of the cases, the sac was excised and examined histopathologically in pathology department. Swabs of the smear were taken in all cases were cultured and antibiotic sensitivity was done. The results were analyzed by using mean, median and the Chi-square $\left(\chi^{2}\right)$ test Results: The maximum incidence of the disease has been in the 4th and 5th decade of life, females were more predominantly affected than the males. The epithelial hypertrophy was the most common histological finding i.e $77.5 \%$, the second common was squamous metaplasia followed by goblet cell formation. Culture and antibiotic sensitivity was done in all cases; out of these the maximum cases were found to be sterile i.e.55\%. The bacteria which have been isolated in the $45 \%$ cases in order of frequency were staphylococcus $20 \%$, streptococcus $12.5 \%$ and pneumococcus $12.5 \%$ respectively. Conclusion: Majority of the chronic dacryocystitis cases are caused by Staphylococcus, streptococcus and pneumococcus. Amoxyclav and 3rd generation cephalosporins can be used to treat chronic dacryocystitis. The epithelial hypertrophy and Non-specific chronic inflammation with fibrosis is indeed the most commonly reported histopathological finding in lacrimal sac wall biopsy specimens. Microbiological analysis and antimicrobial susceptibility pattern is mandatory for the selection of a specific antimicrobial therapy and to the control of further resistance development of bacterial strains.
\end{abstract}

Keywords: Dacrocystitis, Lacrimal sac biopsy, Chronic inflammation, Culture and sensitivity.

\section{Introduction}

Dacryocystitis is an inflammation of the lacrimal sac and duct. It may be congenital or acquired. Acquired dacryocystitis assumes two main forms: acute and chronic [1]. The stagnation of tears due to the obstruction and the resultant accumulation of the debris in the lacrimal sac together act as the potential nidus for the organisms to propagate within the sac, causing inflammation, hyperaemia, oedema and hypertrophy of the mucosal

Manuscript received: $20^{\text {th }}$ May 2017

Reviewed: $30^{\text {th }}$ May 2017

Author Corrected: $8^{\text {th }}$ June 2017

Accepted for Publication: $15^{\text {th }}$ June 2017 epithelium. Accumulation of mucoid and mucopurulent exudates causes the sac to dilate, ultimately leading to a pyocele [2]. The knowledge of the bacteriology of chronic dacryocystitis would contribute to the choice of effective antimicrobial agents and it would also help in reducing the unnecessary load of anti-microbial agents [3]. Chronic dacryocystitis is diagnosed in patients with persistent epiphora and regurgitation of mucoid or mucopurulent material on pressure over the sac area, or regurgitation of mucoid or mucopurulent discharge on irrigation of the lacrimal drainage 
system [4,5]. It is currently believed that the inflammation and fibrosis in patients with nasolacrimal duct obstruction may be secondary to coexisting infectious colonization within the lumen of the lacrimal sac. It is possible that many cases of primary acquired nasolacrimal duct obstruction are in fact secondary to unrecognized low-grade dacryocystitis [6]. Knowledge of the bacteriology of nasolacrimal duct obstruction contributes significantly as well to the choice of prophylactic antimicrobial agents, and it would help in reducing the unnecessary load of anti-microbial agents with subsequent development of resistance patterns in the conjunctival flora with detrementous effects on regimens for prophylaxis on further intraocular surgery [7,8]. During the past years, only few studies had been conducted on the bacteriology of dacryocystitis. Hence, this study was done.

\section{Material and Methods}

The present study was a prospective longitudinal study carried out in department of ophthalmology, Medical College and Hospital of central India. Total 40 cases suffering from different types of chronic dacryocystitis were studied in the eye department. Patients have been selected from ophthalmic outpatient department and those admitted in the eye wards of hospital.

Study design- prospective longitudinal study.

Inclusion criteria- Clinically diagnosed cases of dacryocystitis were included in the study.

Exclusion criteria: The patients who had received either topical or systemic antibiotics for the past one week during their visit to the hospital were excluded.

Collection of data- An informed consent was obtained from all the patients who were enrolled. The specimens were collected with the help of an ophthalmologist. The surrounding area was

\section{Results}

Table No.-1: Age incidence aseptically cleaned, to avoid contamination from the surface microorganisms and the samples were collected in two sterile cotton swabs from the lacrimal sac, either by applying pressure over the lacrimal sac and allowing the purulent material to reflux through the lacrimal punctum or by lacrimal syringing. The sample from the refluxing material was collected by ensuring that the lid margins or the conjunctiva were not touched. One swab was inoculated immediately on plates of MacConkey's agar, 5\% Sheep Blood agar and Chocolate agar and another swab was used for gram staining. The stained smear was screened for the presence or absence of pus cells and bacteria. The isolated organisms were identified by using standard procedures [9]. The sensitivity of the organisms was tested by the Kirby-Bauer disc diffusion method as per the Clinical and Laboratory Standards Institute (formerly NCCLS) guidelines [10]. In all the cases the sac was excised and examined histologically in the pathology department,. Before the commencement of surgery all the cases were subjected to complete local examination of the eye and necessary investigations, concerning the disease, to establish the diagnosis. Swabs of the smear were taken in all the cases and were cultured and antibiotic sensitivity was done. The histiological examinations was done under routine haematoxylene and eosin stains.

Statistical analysis- Chi-square $(\chi 2)$ distribution was used to test the qualitative distribution. A p (predictive) value of $<0.05$ was considered as a significant association between the variables which were tested.

Statistical software: The statistical software SPSS 10.0 was used for the analysis of the data and Microsoft word and excel have been used to generate graphs, tables etc.

\begin{tabular}{|c|c|c|c|}
\hline S.NO. & Age in years & Cases & Percentage \\
\hline 1 & $0-20$ & 1 & $2.5 \%$ \\
2 & $21-30$ & 7 & $17.5 \%$ \\
3 & $31-40$ & 13 & $32.5 \%$ \\
4 & $41-50$ & 12 & $30.0 \%$ \\
5 & $51-60$ & 5 & $12.5 \%$ \\
6 & Above 60 & 2 & $5.0 \%$ \\
\hline & Total & $\mathbf{4 0}$ & $\mathbf{1 0 0 . 0 \%}$ \\
\hline
\end{tabular}


As seen in table no. 1, the maximum incidence of the disease has been in 4 th and 5 th decade of life, i.e $32.5 \%$ in the 4 th and $30.0 \%$ in the 5 th.

Table No.-2: Sex Incidence.

\begin{tabular}{|c|c|c|c|c|c|}
\hline S. No & Type & Male & Percentage & Female & Percentage \\
\hline 1. & I & 12 & $30.0 \%$ & 23 & $57.5 \%$ \\
\hline 2. & II & NIL & NIL & 2 & $5.0 \%$ \\
\hline 3. & III & NIL & NIL & 3 & $7.5 \%$ \\
\hline \multicolumn{2}{|c|}{ Total } & $\mathbf{1 2}$ & $\mathbf{3 0 . 0} \%$ & $\mathbf{2 8}$ & $\mathbf{7 0 . 0} \%$ \\
\hline
\end{tabular}

The incidence of affected females is more than the males being more than double, i.e $70 \%$ females and $30 \%$ males as shown in table no 2 .

Table No.-3: Bacterial infections.

\begin{tabular}{|c|c|c|c|}
\hline S.NO & Organism & Cases & Percentage \\
\hline 1. & Staphylococccus & 8 & $20.0 \%$ \\
\hline 2. & Streptococcus & 5 & $12.5 \%$ \\
\hline 3. & Pneumococcus & 22 & $12.5 \%$ \\
\hline 4. & Sterile & $\mathbf{4 0}$ & $55.0 \%$ \\
\hline & Total & $\mathbf{1 0 0 . 0} \%$ \\
\hline
\end{tabular}

In all the 40 cases the smear for culture and antibiotic sensitivity was done, out of these the maximum cases were found to be sterile i.e 55\%. The bacteria which have been isolated in the $45 \%$ cases in order of frequency were staphylococcus $20 \%$, streptococcus $12.5 \%$ and pneumococcus $12.5 \%$ respectively.

Table No.-4: Histological findings.

\begin{tabular}{|c|c|c|c|}
\hline S.NO & Changes & Cases & Percentage \\
\hline 1. & Hypertrophy & 31 & $77.5 \%$ \\
\hline 2. & Denudation & 15 & $37.5 \%$ \\
\hline 3. & Metaplasia & 23 & $57.5 \%$ \\
\hline 4. & Goblet cell formation & 22 & $55.0 \%$ \\
\hline 5. & Papillae formation & 9 & $22.5 \%$ \\
\hline
\end{tabular}

As shown in above table, the epithelial hypertrophy is the most common histological finding i.e $77.5 \%$, the second most common finding has been squamous metaplasia [57.5\%] followed by goblet cell formation[55\%], denudation $[37.5 \%]$ and papillae formation $[22.5 \%]$.

\section{Table No.-5}

R- Resistant, S- Sensitive, \% S-Percentage sensitive, \% R-Percentage Resistant.

A total of 18 isolates were recovered from 40 lacrimal sac specimens. The Gram positive bacteria outnumbered the Gram negative bacteria. Staphylococcus aureus $(8 / 18 ; 44.4 \% \%)$ were the predominant isolates followed by streptococci $(5 / 18 ; 27.7 \%)$ and pneumococcus $(5 / 18 ; 27.7 \%)$. Amoxyclav, third generation cephalosporin and vancomycin were the most sensitive antibiotics. 
Table No.-5: Antibiogram of streptococcus and Staphylococcus aureus.

\begin{tabular}{|c|c|c|c|c|c|}
\hline & $\mathbf{R}$ & $\mathbf{S}$ & Total & $\mathbf{\% ~ S}$ & $\mathbf{\% ~ R}$ \\
\hline Amoxycillin- Clavulanic acid & 4 & 14 & 18 & 78 & 22 \\
\hline Amikacin & 1 & 8 & 9 & 89 & 11 \\
\hline Cefepime & 3 & 15 & 18 & 83 & 17 \\
\hline Cefotaxime & 3 & 15 & 18 & 83 & 17 \\
\hline Ceftazidime & 3 & 15 & 18 & 83 & 17 \\
\hline Ceftriaxone & 3 & 15 & 18 & 83 & 17 \\
\hline Cefuroxime & 3 & 15 & 18 & 83 & 17 \\
\hline Ciprofloxacin & 9 & 8 & 17 & 47 & 53 \\
\hline Clindamycin & 5 & 12 & 17 & 71 & 29 \\
\hline Co-trimoxazole & 9 & 8 & 17 & 47 & 53 \\
\hline Erythromycin & 12 & 4 & 16 & 25 & 75 \\
\hline Gentamicin & 6 & 12 & 18 & 67 & 33 \\
\hline Imipenem & 3 & 15 & 18 & 83 & 17 \\
\hline Penicillin G & 13 & 5 & 18 & 28 & 72 \\
\hline Piperacillin- Tazobactam & 3 & 15 & 18 & 83 & 17 \\
\hline Vancomycin & 0 & 16 & 16 & 100 & 0 \\
\hline
\end{tabular}

\section{Discussion}

Chronic dacryocystitis is the inflammation of lacrimal sac, frequently caused by bacteria. Obstruction of nasolacrimal duct converts the lacrimal sac a reservoir of infection. It is a constant threat to cornea and orbital soft tissue. Moreover, it causes social embarrassment due to chronic watering from the eye [11].

Under normal conditions, the mucosa of the lacrimal sac is highly resistant to infection. However, infections of the sac and dacryocystitis can be triggered by distal obstruction of the nasolacrimal duct [12]. Dacrocystitis might present in two forms. Acute dacryocystitis is an acute inflammation of the lacrimal sac with tenderness and erythema of the overlying tissues and $23 \%$ of eyes might present with lacrimal abscess $[12,13]$.

There is a varied spectrum of its clinical presentations ranging from tenderness and erythema of the overlying tissues to a frank lacrimal abscess [14]. Untreated lacrimal abscess can progress to orbital cellulitis, superior ophthalmic vein thrombosis, and cavernous sinus thrombosis $[15,16]$.

Most of the studies on the microbiological profile of dacryocystitis are on chronic dacryocystitis $[17,18,19]$. Very few of them deal with acute dacryocystitis [20,21,22], and only one discusses lacrimal abscess superficially [20]. The general trend in chronic dacryocystitis reflects culturepositive rates ranging from $52.5 \%$ to $97.3 \%$ with isolation rates of gram-positive organisms ranging from $53.7 \%$ to $75 \%$ and those of gram-negative organisms from $25 \%$ to $37.4 \%$ [23].

The most common gram-positive organisms isolated include $S$. aureus (worldwide), $S$. pneumoniae (Africa), and S. epidermidis (USA). Among the gram-negative isolates, there is a variable predominance like that of $H$. influenzae (Middle East), P. aeruginosa (North India and USA), E. coli (Europe), and Corynebacterium diphtheriae (China) [17,18,19].

In our study we found Majority of the chronic dacryocystitis cases are caused by Staphylococcus, streptococcus and pneumococcus A total of 18 isolates were recovered from 40 lacrimal sac specimens. The Gram positive bacteria out numbered the Gram negative bacteria.

Staphylococcus aureus (8/18; 44.4\%\%) were the predominant isolates followed by streptococci $(5 / 18 ; 27.7 \%)$ and pneumococcus $(5 / 18 ; 27.7 \%)$. Amoxyclav, third generation cephalosporin and vancomycin were the most sensitive antibiotics. 
Mohammad Javed Ali [24] found that, the mean age at presentation was 37 years. The female to male ratio was $2: 1$. There was no significant difference in the laterality between the right and left eyes. Gram-positive organisms were the most commonly isolated accounting for $56.3 \%$ (63/112), and the commonest species isolated was Staphylococcus aureus in $25 \%$ (28/112) of the patients. Hemophilus influenzae was the commonest gram-negative isolate accounting for $30.2 \%$ of all the gram-negative isolates. Of the patients, $10.7 \%(12 / 112)$ showed no organisms on smear as well as sterile cultures. Gram-positive organisms were commonly sensitive to penicillins and vancomycin whereas gram-negative organisms were sensitive to quinolones and aminoglycosides.

In our study the maximum incidence of the disease has been in 4 th and 5 th decade of life, i.e $32.5 \%$ in the 4 th and $30.0 \%$ in the 5 th decade and gram positive organisms were the most common. The cultures of our study weresensitive to amoxyclav, cephalosporins and vancomycin.

Relhan N1, Albini TA et al[25] found that Endophthalmitis caused by Gram-positive organisms with reduced vancomycin susceptibility and/or resistance is an important clinical issue worldwide, The causative organisms included Enterococcus species (7/27), coagulase-negative staphylococci (4/27), Staphylococcus aureus (4/27), Bacillus species (4/27), Streptococcus species (3/27), Leuconostoc species (3/27), Staphylococcus hominis (1/27), and unidentified Gram-positive cocci $(1 / 27)$. Visual acuity of $20 / 400$ or better at the final follow-up was recorded in 10/26 patients (38.5\%; data were not available for one patient). Treatment options include fluoroquinolones, penicillin, cephalosporins, tetracyclines, and oxazolidinones.

Similarly Assefa Y et al [26] also found that From the total of 51 dacryocystitis cases, bacterial origins were isolated among $31(60.8 \%)$ cases. The dominant isolates were Coagulase negative Staphylococci (CNS) 9(29.0\%), Staphylococcus aureus (S. aureus) 6(19.4\%), and Pseudomonas species 3(9.7\%). S. pneumoniae, Entrobacter species, K. pnemoniae and H. influenzae were each accounted $6.5 \%$ isolation rate. Among the commonly prescribed antimicrobials tested for susceptibility pattern; amoxicillin 38.7\%, ciprofloxacin $25.8 \%$, chloramphinicol $25.8 \%$, cotrimoxazole $25.8 \%$, and ampicillin $19.4 \%$ were resistant to the overall bacterial isolates identified. Teweldemedhin $\mathrm{M}$ et al [27] Among 270 study subjects, $180(66.7 \%)$ were culture positive for different bacterial isolates. The predominant bacterial isolates were Staphylococcus aureus (40, $22.2 \%$ ), coagulase negative staphylococci (31, $17.2 \%)$ and Pseudomonas aeruginosa (21, 11.7\%). Ocular surface disease, ocular trauma, hospitalization and cosmetic application practices were significantly associated with the occurrence of bacterial infection.

Concerning antimicrobial susceptibility, most isolates were susceptible to amikacin $(137,93.2 \%)$, gentamicin $(131,89.1 \%)$ and ciprofloxacin (141, $89.2 \%)$. Overall, 40 (22.5\%), $34(19.1 \%)$ and 62 $(34.8 \%)$ isolates were resistant to one, two, and three or more antimicrobials, respectively.

Similar to our study, Bernardini FP et al [28] found that Findings of histopathologic evaluation of 302 lacrimal sac specimens from 170 females and 88 males who had undergone routine DCR were reviewed. Evidence of systemic disease or neoplasia involving the lacrimal sac was present in 10 specimens. All 10 positive specimens had a grossly abnormal appearing $\mathrm{sac}$ at the time of surgery $(\mathrm{n}=8)$, a known preexisting history of systemic diseases $(n=6)$, or both. The remaining 292 specimens showed chronic inflammation, fibrosis, or normal mucosa. Alkatan $\mathrm{H}$ et al [29] found that Out of the 459 patients initially included, the mean age was $51.63 \pm 17.8$ years.

Female patients constituted $70.8 \%$ while male patients accounted for $29.2 \%$. Malignancy was suspected before surgery in 3 cases of the 498 specimens reviewed $(0.6 \%)$. The remaining 495 specimens analyzed, 17 cases (3.43\%) had unsuspected tissue diagnosis (other than chronic dacryocystitis) including Oncocytoma in 7 , dacryolith in 7 and granulomas in 3. However, no case of malignant neoplasm was identified.

\section{Conclusion}

The prevalence of bacterial pathogens among external ocular samples was high and the predominant isolate was Staphylococci. Exceptionally high resistance was observed among Gram positive bacterial isolates that may dictate to 
conduct drug susceptibility test routinely. There were no unsuspected malignant cases in the current series. Therefore routine histopathological examination of DCR specimens is not considered to be essential. It should be reserved only for selected suspicious cases

Therefore, identification of the etiologic agent and antimicrobial susceptibility testing should be practiced to select the appropriate antimicrobial agent to treat eye infections and prevent the emergence of drug resistant bacteria. Though the information derived from this study was very meaningful, further studies encompassing viral, fungal, parasitic and anaerobic bacterial origin are important to better define the spectrum and relative incidence of pathogens causing dacryocystitis.

\section{Funding: Nil, Conflict of interest: None Permission of IRB: Yes}

\section{References}

1. Gupta AK, Raina UK, Gupta A. The Lacrimal Apparatus. In: Text Book of Opthalmology. 1st edn. New Delhi, BI Churchill Livingstone 1999; 275-77.

2. Nayak N. Fungal infections of the eye-laboratory diagnosis and treatment. Nepal Med Coll J. 2008 Mar;10(1):48-63.

3. Chaudhary M, Bhattarai A, Adhikari SK, Bhatta DR. Bacteriology and antimicrobial susceptibility of adult chronic dacryocystitis. Nepal J Ophthalmol. 2010 Jul-Dec;2(2):105-13. doi: 10. 3126 / nepjoph.v2i2.3716.

4. Bartley GB. Acquired lacrimal drainage obstruction: an etiologic classification system, case reports, and a review of the literature. Part 1. Ophthal Plast Reconstr Surg. 2003; 8 (4): 237-242.

5.Hartikainen J, Lehtonen OP, Saari KM. Bacteriology of lacrimal duct obstruction in adults. Br J Ophthalmol. 2009;81(1):37-40.

6. Das JK, Deka AC, Kuri GC, Bhattacharjee K, Das D, Gogoi K. Bacteriology of chronic dacryocystitis in adult population of northeast India. Orbit. 2008;27(4):243-7. doi: 10.1080/ 0167 6830802224668.
7. Chaudhary M, Bhattarai A, Adhikari SK. Bacteriology and antimicrobial susceptibility of adult chronic dacryocystitis. Nep J Oph. 2010;2 (4):105-113.

8. Walland MJ, Rose GE. Soft tissue infections after open lacrimal surgery. Ophthalmol. 2011; 101 (3): 608-11.

9. Collee JG, Miles RS, Watt B. Tests for the identification of bacteria. In:Collee JG, Fraser AG, Marmion BP, Simmons A. Mackie and McCartney, Practical Medical Microbiology, 14th ed. New Delhi: Elsevier, 2006; 13149.

10. Matthew AW, Franklin RC, William AC, Michael ND, George ME, David WH, et al. Performance Standards for Antimicrobial Susceptibility Testing; Fifteenth Informational supplement. 2005; 25 (1) : 19-33. www.jcdr. net/article

11. Mandal R, Banerjee AR, Biswas MC, Mondal A, Kundu PK, Sasmal NK. Clinicobacteriological study of chronic dacryocystitis in adults. J Indian Med Assoc. 2008 May;106(5):296-8.

12. Ali MJ, Joshi SD, Naik MN, Honavar SG. Clinical profile and management outcome of acute dacryocystitis: two decades of experience in a tertiary eye care center. 2013

13. Ali MJ, Motukupally SR, Joshi SD, Naik MN. The microbiological profile of lacrimal abscess: two decades of experience from a tertiary eye care center. J Ophthalmic Inflamm Infect. 2013 Jul 27;3 (1): 57. doi: 10.1186/1869-5760-3-57.

14. Kikkawa DO, Heinz GW, Martin RT, Nunery WN, Eiseman AS. Orbital cellulitis and abscess secondary to dacryocystitis. Arch Ophthalmol. 2002 Aug;120(8):1096-9.

15. Maheshwari R, Maheshwari S, Shah T. Acute dacryocystitis causing orbital cellulitis and abscess. Orbit. 2009;28(2-3):196-9.

16. Schmitt NJ, Beatty RL, Kennerdell JS. Superior ophthalmic vein thrombosis in a patient with dacryocystitis induced orbital cellulitis. Ophthal Plast Reconstr Surg. 2005;3:387-389. doi:10.1097/ 01.iop.0000176269.84949.96. 
17. Chaudhry IA, Shamsi FA, Al-Rashed W. Bacteriology of chronic dacryocystitis in a tertiary eye care center. Ophthal Plast Reconstr Surg. 2005 May; 21(3):207-10.

18. Das JK, Deka AC, Kuri GC, Bhattacharjee K, Das D, Gogoi K. Bacteriology of chronic dacryocystitis in adult population of northeast India. Orbit. 2008;27(4):243-7. doi: 10.1080/ 0167 6830802224668 .

19. Kebede A, Adamu Y, Bejiga A. Bacteriological study of dacryocystitis among patients attending in Menelik II hospital, Addis Ababa, Ethiopia. Ethiop Med J. 2010;3:29-33.

20. Briscoe D, Rubowitz A, Assia E. Changing bacterial isolates and antibiotic sensitivities of purulent dacryocystitis. Orbit. 2005;3:95-98. doi: 10. $1080 / 01676830590926585$.

21. Mills DM, Bodman MG, Meyer DR, Morton AD 3rd. The microbiologic spectrum of acute dacryocystitis. A national study of acute versus chronic infection. Ophthal Plast Reconstr Surg. 2007; 3: 302-306. doi: 10. 1097/IOP. 0b013e $318070 \mathrm{~d} 237$.

22. Razavi ME, Ansari-Astaneh MR, Farzadnia M, Rahmaniyan H, Moghiman T. Bacteriological evaluation of adult dacryocystitis in Iran. Orbit. 2010 Oct;29(5):286-90. doi: 10.3109/0167683 1003664293. Epub 2010 Aug 16.

23. Sun X, Liang Q, Luo S, Wang Z, Li R, Jin X. Microbiological analysis of chronic dacryocystitis. Ophthalmic Physiol Opt. 2005;3:261-263. doi: 10.1111/j.1475-1313.2005.00284.x.

24. Mohammad Javed Ali,囚1 Swapna R Motukupally, The microbiological profile of lacrimal abscess: two decades of experience from a tertiary eye care center $\mathbf{J}$ Ophthalmic Inflamm Infect. 2013; 3: 57.

Published online 2013 Jul 27. doi: 10.1186/18695760-3-57.

25. Relhan N1, Albini TA1, Pathengay A Endophthalmitis caused by Gram-positive organisms with reduced vancomycin susceptibility: literature review and options for treatment. $\mathrm{Br} \mathrm{J}$ Ophthalmol. 2016 Apr;100(4):446-52. doi: 10.1136 / bjophthalmol-2015-307722. Epub 2015 Dec 23.

26. Assefa Y1, Moges F et al Bacteriological profile and drug susceptibility patterns in dacryocystitis patients attending Gondar University Teaching Hospital, Northwest Ethiopia. BMC Ophthalmol. 2015 Apr 2;15:34. doi: 10.1186 / s12886-015-0016-0.

27. Teweldemedhin M1,2, Saravanan M Ocular bacterial infections at Quiha Ophthalmic Hospital, Northern Ethiopia: an evaluation according to the risk factors and the antimicrobial susceptibility of bacterial isolates. BMC Infect Dis. 2017 Mar 14; 17(1):207. doi: 10.1186/s12879-017-2304-1.

28. Bernardini FP1, Moin M, Routine histopathologic evaluation of the lacrimal sac during dacryocystorhinostomy: how useful is it? Ophthalmology.2002 Jul;109(7):1214-7; discussion 1217-8.

29. Alkatan H1, Al-Qurashi M Is routine histopathological examination of dacryocystorhinostomy / dacryocystectomy specimens necessary? A tertiary eye hospital experience. Can J Ophthalmol. 2017 Feb; 52(1):34-41. doi: 10. 1016/j. jcjo.2016.08.004. Epub 2016 Nov 17.

\section{How to cite this article?}

Saxena SP, Gupta SC, Gupta S, Sharma S, Saxena R. Clinicobacterial and histopathological study of chronic dacryocystitis. Int J Med Res Rev 2017;5(06):562-568. doi:10.17511/ijmrr. 2017.i06.04. 